ISSN: 1410-8917

Jurnal Kimia Sains \& Aplikasi

e-ISSN: 2597-9914

\section{Jurnal Kimia Sains dan Aplikasi Journal of Scientific and Applied Chemistry}

Journal homepage: http://ejournal.undip.ac.id/index.php/ksa

\title{
Synthesis of Zeolite from Bagasse and Rice Husk Ashes as Surfactant Builder on Detergency Process: Variation of $\mathrm{NaOH}$ Concentration for Silica Isolation
}

\author{
Arnelli $^{\mathrm{a}^{*}}$, Bara Yunianto Fathoni ${ }^{\mathrm{a}}$, Teguh Iman $\mathrm{P}^{\mathrm{a}}$, Ahmad Suseno ${ }^{\mathrm{a}}$, Yayuk Astuti $^{\mathrm{a}}$ \\ a Chemistry Department, Faculty of Sciences and Mathematics, Diponegoro University, Jalan Prof. Soedarto, Tembalang, Semarang \\ * Corresponding author: arnelli@live.undip.ac.id
}

https://doi.org/10.14710/jksa.21.3.139-143

\begin{tabular}{l} 
Article Info \\
\hline Article history: \\
Received: 1 July 2018 \\
Revised: 25 July 2018 \\
Accepted: 26 July 2018 \\
Online: 31 July 2018 \\
\hline
\end{tabular}

Keywords:

zeolite; surfactant builder; detergency; rice husk; ash bagasse

\begin{abstract}
Zeolite was successfully synthesised from ash bagasse and from rice husk ash as source of silica and applied to surfactant builder. The removal of silica from bagasse ash and from rice husk ash was influenced by $\mathrm{NaOH}$ concentration to obtain sodium silicate. This research aimed to synthesize zeolite, determine the optimum concentration of $\mathrm{NaOH}$ to synthetic zeolite, identify the zeolite mineral type, morphology, determine cation exchange rate and detergency by using synthesized zeolite as builder. Synthesis of zeolite was undertaken by sol-gel method followed by hydrothermal process. The stages of this study included the production of bagasse and rice husk ashes, isolation of silicate using a variation of $\mathrm{NaOH}$ concentration of $1.67,3.33,5.00,6.67$ and $8.30 \mathrm{M}$ in the form of sodium silicate. Synthesis of zeolite was carried out by reacting sodium silicate and sodium aluminate using hydrothermal method. The synthesized zeolites were characterized using XRD and SEM. The results of this research indicated the types of zeolite minerals formed, namely, zeolite A, Na-A, Na-Y and sodalite. The morphology of the synthesized zeolites from both samples was quite homogeneous, $\mathrm{NaOH}$ concentration used to produce zeolite from bagasse ash was $1.67 \mathrm{M}$ with value of cation exchange capacity (CEC) and detergency were respectively $121.14 \mathrm{mek} / 100$ gram and $92.09 \%$ while synthesis zeolite from rice husk ash was generated using $8.3 \mathrm{M} \mathrm{NaOH}$ concentration with value of cation exchange capacity (CEC) and detergency were 65,71 mek / 100 gram and 94,313\%, respectively.
\end{abstract}

Kata Kunci: zeolit; builder surfaktan; detergensi; sekam padi; ampas tebu

\section{Abstrak}

Telah dilakukan sintesis zeolit dari abu ampas tebu dan dari abu sekam padi sebagai sumber silika dan diaplikasiikan untuk builder surfaktan. Pengambilan silika dari abu ampas tebu dan dari abu sekam padi dipengaruhi oleh konsentrasi $\mathrm{NaOH}$ untuk menperoleh natrium silikat. Penelitian ini bertujuan untuk mensintesis zeolit, menentukan konsentrasi optimum $\mathrm{NaOH}$ terhadap zeolit sintetsis, jenis mineral zeolit, morfologi, menentukan nilai tukar kation dan deterjensi dengan menggunakan zeolit hasil sintesis sebagai builder. Sintesis zeolit dilakukan dengan metode sol-gel dilanjutkan proses hidrotermal. Tahapan penelitian ini meliputi pengabuan ampas tebu dan pengabuan sekam padi, pengambilan silikat menggunakan variasi konsentrasi $\mathrm{NaOH} 1,67 ; 3,33 ; 5 ; 6,67$ dan 8,3 M sebagai natrium silikat. Sintesis zeolit dilakukan 
dengan mereaksikan natrium silikat dengan natrium aluminat kemudian dilanjutkan proses hidrotermal. Zeolit hasil sintesis dikarakterisasi menggunakan XRD dan SEM. Hasil penelitian ini menunjukkan Jenis mineral zeolit yang terbentuk antara lain zeolit A, Na-A, Na-Y dan sodalit. Morfologi zeolit hasil sintesis dari kedua sampel cukup homogen, konsentrasi $\mathrm{NaOH}$ optimum adalah1,67 M dengan nilai kapasitas tukar kation (KTK) dan detergensi berturut-turut 121,14 mek/100 gram dan 92,09 \% untuk sampel abu ampas tebu sedangkan zeolit sintesis dari abu sekam padi optimum pada konsentrasi $\mathrm{NaOH}$ 8,3 M dengan nilai KTK dan detergensi yaitu 65,71 mek/100 gram dan $94,313 \%$.

\section{Introduction}

Abu ampas tebu tersusun dari beberapa jenis partikel dengan komposisi ukuran, morfologi dan kandungan kimia yang berbeda. Partikel-partikel halus sebagian besar berisi silika yang jumlahnya sebesar $49,58 \%$ sementara itu abu sekam padi mengandung 91,65\%. Silika dapat diisolasi menggunakan metode alkali konvensional sehingga pada pengambilan silika dari abu ampas tebu dan dari abu sekam padi sangat dipengaruhi oleh konsentrasi $\mathrm{NaOH}$ yang digunakan, Silika yang diperoleh kemudian dapat digunakan untuk sintesis material berbasis silika seperti zeolit ([1].

Zeolit adalah mineral aluminosilikat terhidrasi dengan struktur tiga-dimensi terbuka sehingga dapat dimanfaatkan sebagai adsorben atau penukar kation. Zeolit dapat disintesis dengan menggunakan metode sol gel yang dilanjutkan proses hidrotermal [2]. Berdasarkan penelitian Hanipa $d k k$. [3] zeolit-A terbentuk pada proses hidrotermal selama 1,2 dan 3 hari. Kemampuan zeolit dalam pertukaran kation dapat dimanfaatkan oleh industri, salah satunya pada industri deterjen sebagai builder [4]. Zat pembangun (builder) pada deterjen berfungsi dalam meningkatkan efisiensi pencuci dari surfaktan dengan cara menonaktifkan mineral penyebab kesadahan air (ion $\mathrm{Ca}^{2+}$ dan $\mathrm{Mg}^{2+}$ ).

Banyak diantara deterjen yang menggunakan builder jenis sodium tripolyphosphate (STPP) dan tetra sodium pyrophosphate (TSPP), namun builder jenis tersebut dapat menyebabkan deposit fosfat dalam air dan berakibat eutrofikasi [5]. Zeolit mampu menggantikan peran fosfat sebagai pembentuk builder dalam deterjen, karena zeolit dapat mencegah pembentukan garam-garam anorganik yang kurang larut dalam air [4].

Penelitian ini akan dilakukan sintesis zeolit berbahan dasar abu ampas tebu dan abu sekam padi sebagai sumber Si menggunakan metode sol gel yang dilanjutkan proses hidrotermal, dengan variasi konsentrasi $\mathrm{NaOH}$ 1,67; 3,33; 5; 6,67 dan 8,3 M. Zeolit hasil sintesis kemudian diaplikasikan sebagai builder dalam proses deterjensi.

Penelitian ini bertujuan untuk mensintesis zeolit, menentukan konsentrasi optimum $\mathrm{NaOH}$ terhadap zeolit sintetsis, jenis mineral zeolit, morfologi, menentukan nilai tukar kation dan deterjensi dengan menggunakan zeolit hasil sintesis sebagai builder.

\section{Metodologi Penelitian}

\section{Bahan}

Bahan-bahan yang digunakan dalam penelitian ini adalah $\mathrm{NaOH}$, abu ampas tebu, abu sekam padi, $\mathrm{Al}(\mathrm{OH})_{3}$, $\mathrm{H}_{2} \mathrm{O}$, kain katun, Soduim Lauryl Sulfat, kotoran standart dan $\mathrm{Na}_{2} \mathrm{SO}_{4}$.

\section{Pembuatan Abu Ampas Tebu dan abu sekam padi}

Ampas tebu dan sekam padi dicuci, kemudian dikeringkan di bawah sinar matahari hingga kering, kemudian diarangkan. Arang yang diperoleh kemudian difurnace selama 4 jam dengan suhu $700^{\circ} \mathrm{C}$ kemudian didinginkan dan dihaluskan.

\section{Pengambilan Natrium Silikat}

Sebanyak 10 gram abu yang diperoleh dilarutkan ke dalam $50 \mathrm{~mL} \mathrm{NaOH}$ dengan berbagai konsentrasi yaitu $1.67,3.33,5,6.67$ dan $8,3 \mathrm{M}$, distirer selama 2 jam $300 \mathrm{rpm}$ pada suhu $80^{\circ} \mathrm{C}$ kemudian disaring dan filtratnya sebagai natrium silikat.

\section{Pembuatan Natrium Aluminat}

Sebanyak $20 \mathrm{~g} \mathrm{NaOH}$ yang dilarutkan dalam $100 \mathrm{~mL}$ akuades dipanaskan dan di tambahkan $8,5 \mathrm{~g} \mathrm{Al}(\mathrm{OH})_{3}$ disertai pengadukan.

\section{Sintesis Zeolit}

Sebanyak $25 \mathrm{~mL}$ natrium Silikat (5 variasi konsentrasi $\mathrm{NaOH}$ ) dan $25 \mathrm{~mL}$ natrium Aluminat dicampurkan kemudian diaduk menggunakan magnetic stirrer selama 2 jam pada 300 rpm sehingga terbentuk gel. Selanjutnya dimasukkan ke dalam autoclave dan dipanaskan pada suhu $100^{\circ} \mathrm{C}$ selama 340 menit dalam keadaan tertutup rapat. Hasil yang terbentuk kemudian di saring dengan kertas saring Whatmann. Padatan yang terbentuk kemudian dicuci dengan Aquades hingga $\mathrm{pH}$ filtrat $10-11$. Selanjutnya dikeringkan pada suhu $100^{\circ} \mathrm{C}$ selama 12 jam [2], dikarakterisasi dan digunakan sebagai buider.

\section{Proses Deterjensi}

Detergensi adalah sifat spesifik dari zat aktif permukaan (Surfaktan) untuk membersihkan suatu permukaan dari kotoran [6]. Proses deterjensi dilakukan dengan cara kain ukuran tertentu dikotori dengan kotoran standar, dikeringkan dan ditimbang dicatat 
sebagai berat kain kotor. Kotoran standar terbuat dari campuran kaolin, feriklorida, karbon hitam, bensin mobil dan lemak sapi, masing-masing disuspensikan dalam aseton. Kain kotor kemudian dicuci dengan larutan surfaktan dengan penambahan zeolit hasil sintesis sebagai builder. Kain di bilas, dikeringkan dan ditimbang dan di catat berat bersihnya. Sebagai pembanding digunakan Sodium tripolyphosphate (STPP) sebagai builder. Penentuan persentase deterjensi digunakan persamaan sebagai berikut:

$$
\text { Detergensi }=\frac{B K L}{B K M} \times 100 \%
$$

di mana BKL merupakan jumlah kotoran yang lepas dan BKM adalah jumlah kotoran yang menempel.

\section{Hasil dan Pembahasan}

\section{Sintesis Zeolit}

Penghilangan kandungan karbon dari ampas tebu dan dari sekam padi dilakukan dengan cara pengabuan arang dengan pemanasan suhu tinggi pada $700^{\circ} \mathrm{C}$ selama 4 jam. Pengabuan pada suhu $700^{\circ} \mathrm{C}$ bertujuan untuk mendapatkan Si dalam fasa amorf. Silika dalam kondisi fasa amorf memiliki sifat kelarutan yang khas, di mana silika amorf mempunyai kelarutan yang tinggi pada kondisi alkalis dari pada silika yang berbentuk kristalin contohnya mullite dan kuarsa [2]. Dalam proses pengabuan, hidrokarbon dalam kedua sampel teroksidasi menghasilkan $\mathrm{CO}_{2}$ dan $\mathrm{H}_{2} \mathrm{O}$ yang menguap sehingga yang tersisa adalah bahan anorganik terutama $\mathrm{SiO}_{2}$.

Abu ampas tebu ditambahkan $\mathrm{NaOH}$ dengan variasi konsentrasi 1,67; 3,33; 5; 6,67 dan 8,3 M untuk mendapatkan larutan natrium silikat [2]. Reaksinya:

$$
\mathrm{SiO}_{2(s)}+2 \mathrm{NaOH}_{(\mathrm{l})} \rightarrow \mathrm{Na}_{2} \mathrm{SiO}_{3(\mathrm{l})}+\mathrm{H}_{2} \mathrm{O}_{(\mathrm{l})}
$$

Tujuan variasi $\mathrm{NaOH}$ yaitu untuk mengetahui pengaruh konsentrasi $\mathrm{NaOH}$ terhadap berat produk zeolit yang terbentuk. Penggunaan konsentrasi $\mathrm{NaOH} \mathrm{1,67} \mathrm{M}$ dengan volume $\mathrm{NaOH} 50 \mathrm{~mL}$ mengakibatkan silika yang terdapat dalam abu ampas tebu tidak habis. Silika dalam abu ampas tebu mulai habis pada konsentrasi $\mathrm{NaOH}$ 3,33 M karena berdasarkan stoikiometri untuk 10 gram abu ampas tebu dengan kandungan $\mathrm{SiO}_{2}$ sebesar 34,7806\% (0,0579 mol) dibutuhkan minimal 0,1158 mol $\mathrm{NaOH}$ sehingga reaksi tersebut sesuai dengan stoikiometri reaksi perbandingan koefisien dan mol. Sementara itu silika dalam sampel abu sekam padi lebih banyak dari abu ampas tebu maka konsentrasi $\mathrm{NaOH} \mathrm{8,3} \mathrm{M}$. Sumber alumina dalam sintesis zeolit adalah natrium aluminat yang dibuat dari $\mathrm{Al}(\mathrm{OH})_{3}$ di tambahkan $\mathrm{NaOH}$. Reaksinya:

$$
\mathrm{Al}(\mathrm{OH})_{3}(\mathrm{~s})+\mathrm{NaOH}_{(\mathrm{l})} \rightarrow \mathrm{NaAl}(\mathrm{OH})_{4(\mathrm{l})}
$$

Pada reaksi antara natrium silikat dengan natrium aluminat terbentuk gel. berwarna putih yang memperlihatkan adanya interaksi antara natriumsilikat dan natrium aluminat. Pada proses tersebut terjadi reaksi kondensasi dan diikuti oleh polimerisasi larutan jenuh membentuk ikatan Si-O-Al. Berdasarkan penelitian
Wang $d k k$. [2] sintesis zeolit A memberikan hasil yang optimum pada waktu hidrotermal 340 menit, menurut Arnelli $d k k$. [7] menyatakan bahwa waktu hidrotermal dapat mempengaruhi nilai kapasitas tukar kation maka dalam sintesis zeolit ini digunakan perlakuan waktu hidrotermal selama 340 menit dengan suhu $100^{\circ} \mathrm{C}$ (Sumber silika dari abu ampas terbu) sedangkan berdasarka penelitian Arnelli dkk. [8] bila sumber silika dari abu sekam padi waktu hidrotermal optimum pada 420 menit dengan suhu $100^{\circ} \mathrm{C}$ akan terbentuk zeolit NaA.

Pada proses hidrotermal, gel amorf akan mengalami penataan ulang pada struktur zeolitnya. Struktur zeolit tersebut akan lebih teratur dan ikatannya lebih kuat sehingga dapat terbentuk embrio inti kristal [9].

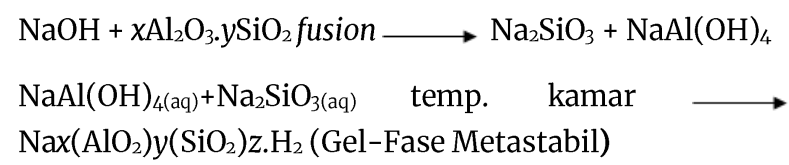

Kristal zeolit hasil proses hidrotermal disaring kemudian dicuci dengan akuabides. Pencucian ini bertujuan untuk menurunkan $\mathrm{pH}$ filtrat dari 14 sampai antara 10-11. Padatan yang terbentuk kemudian di panaskan untuk menghilangkan molekul air yang terperangkap secara bebas pada zeolit. Zeolit yang terbentuk berupa padatan putih dan tidak ada perbedaan yang siknifikan antara sifat fisik zeolit dengan konsentrasi $\mathrm{NaOH}$. XRD dari kelima variasi $\mathrm{NaOH}$ baik untuk abu ampas tebu maupun abu sekam padi berupa mineral yang sama yaitu zeolit $\mathrm{Na}-\mathrm{Y}$, zeolit $\mathrm{Na}-\mathrm{A}$, zeolitA dan sodalit.

\section{Karakterisasi dengan X-Ray Diffractometer (XRD)}

Penentuan jenis mineral menggunakan data JCPDSICDD nomor 11-0401 (Sodalit/ $\mathrm{Na}_{4}\left(\mathrm{Al}_{3} \mathrm{Si}_{3} \mathrm{O}_{12}\right) \mathrm{OH}$ ), nomor 31-1269 (zeolit A/ $\mathrm{Na}_{12} \mathrm{Al}_{12} \mathrm{Si}_{12} \mathrm{O}_{48} . \mathrm{xH}_{2} \mathrm{O}$ ), nomor 43-0168 (zeolit Na-Y/ $\mathrm{Na}_{2} \mathrm{Al}_{2} \mathrm{Si}_{4.5} \mathrm{O}_{13} \mathrm{xH}_{2} \mathrm{O}$ ), dan nomor 38-0241 (zeolit Na-A/ $\mathrm{Na}_{2} \mathrm{Al}_{2} \mathrm{Si}_{1.85} \mathrm{O}_{7.7} 5.1 \mathrm{H}_{2} \mathrm{O}$ ).

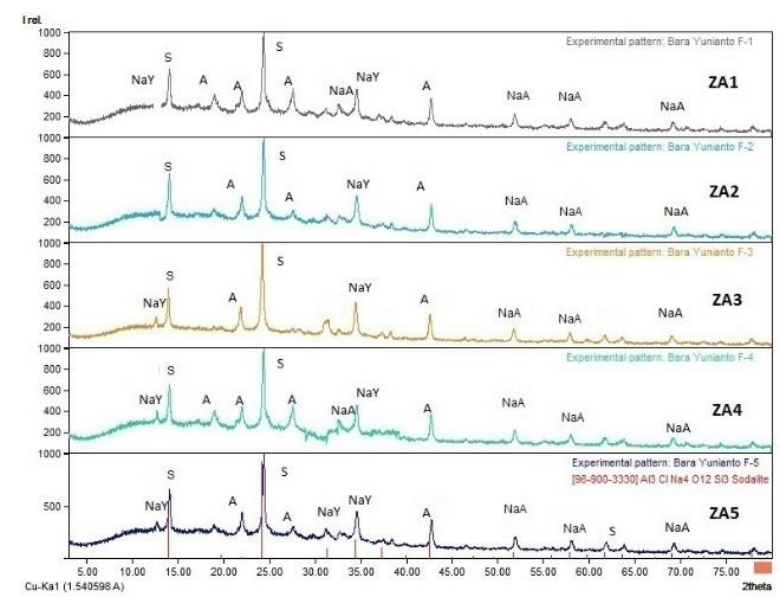

Gambar 1: Difraktogram Zeolit Hasil Sintesis dari abu ampas tebu 


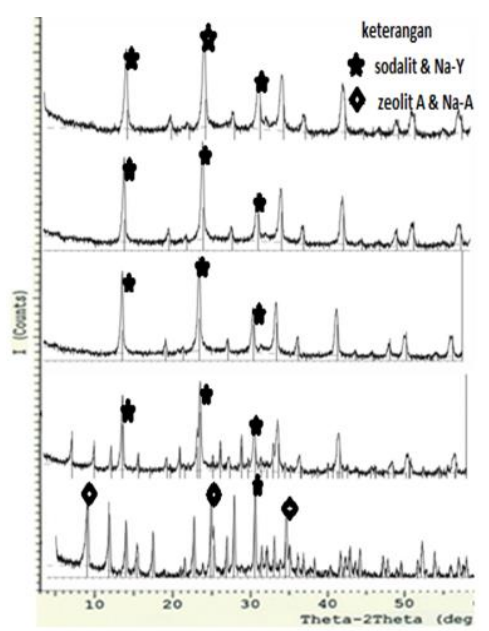

Gambar 2: Difraktogram Zeolit Hasil Sintesis dari abu sekam padi

Gambar 1 menunjukkan hasil analisa XRD pada kelima sampel zeolit hasil sintesis dari abu ampas tebu dengan keterangan ZA1, ZA2, ZA3, ZA4, ZA5 berturut turut merupakan zeolit hasil sintesis dengan variasi konsentrasi $\mathrm{NaOH}$ sebesar 1,67; 3,33; 5; 6,67 dan 8,3 $\mathrm{M}$. Puncak A, HS, NaA dan NaY pada XRD berturut-turut merupakan jenis mineral zeolit yang terbentuk yaitu zeolit A, sodalit, zeolit Na-A dan zeolit Na-Y. Pada gambar 2 (XRD zeolit sintesis dari abu sekam padi) juga menunjuk adanya mineral zeolit $\mathrm{A}$, sodalit, zeolit $\mathrm{Na}-\mathrm{A}$ dan zeolit Na-Y. Ketidakmurnian zeolit yang terbentuk atau tidak terbentuknya zeolit dengan satu jenis mineral zeolit tertentu dikarenakan orientasi pembentukan kristal pada mineral zeolit tersebut kurang maksimal. Hal ini disebabkan pembentukan kerangka zeolit berbeda sesuai dengan waktu yang dibutuhkan dan rasio Si/Al.

\section{Karakterisasi dengan Scanning Electron Microscopy (SEM)}

Analisa sampel menggunakan SEM dilakukan pada sampel zeolit hasil sintesis dengan variasi konsentrasi $\mathrm{NaOH}$ 1,67 M dan 8,3 M. Hal tersebut dilakukan karena pada hasil analisa KTK, zeolit hasil sintesis menunjukkan kecenderungan nilai KTK semakin turun berdasarkan kenaikan konsentrasi $\mathrm{NaOH}$. Selain itu, pengambilan sampel dari variasi konsentrasi $\mathrm{NaOH}$ terendah $(1,67 \mathrm{M})$ dan tertinggi $(8,3 \mathrm{M})$ diharapkan mampu memberikan gambaran morfologi dan homogenitas dari permukaan zeolit hasil sintesis berdasarkan kenaikan konsentrasi $\mathrm{NaOH}$.

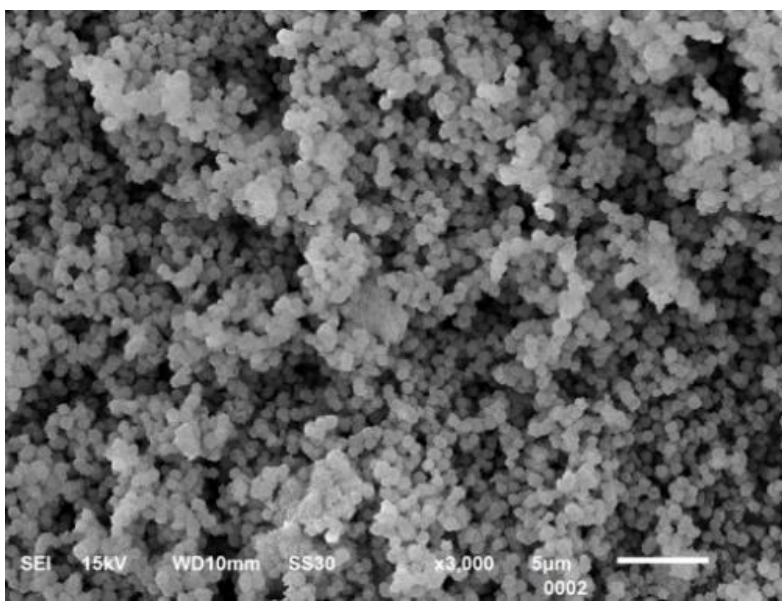

Gambar 3 Hasil SEM zeolit hasil sintesis dengan konsentrasi $\mathrm{NaOH} 1,67 \mathrm{M}$

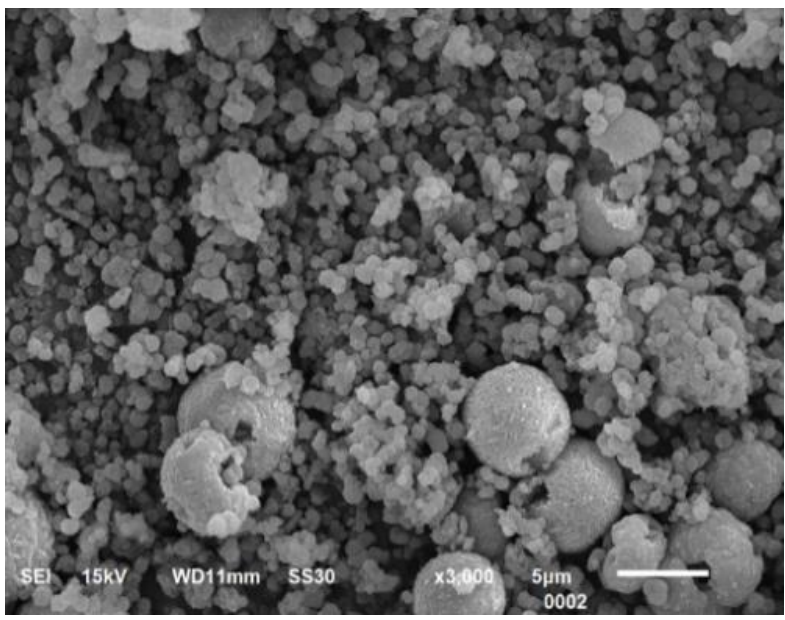

Gambar 4 Hasil SEM zeolit hasil sintesis dengan konsentrasi $\mathrm{NaOH} \mathrm{8,3} \mathrm{M}$

Pada Gambar 3 terlihat morfologi pada zeolit pada $\mathrm{NaOH}$ 1,67 Mhalus dengan diameter grain lebih kecil dari pada zeolit hasil sintesis dengan konsentrasi $\mathrm{NaOH} 8,3 \mathrm{M}$ (Gambar 4). Selain itu, pada zeolit ini mempunyai tekstur grain yang lebih homogen dibanding dengan zeolit hasil sintesis dengan konsentrasi $\mathrm{NaOH}$ 8,3 $\mathrm{M}$.

\section{Kapasitas Tukar Kation}

Hasil kapasitas tukar kation pada zeolit hasil sintesis dapat dilihat pada Tabel 1. Berdasarkan tabel 1 nilai KTK yang paling tinggi adalah pada ZA1 sebesar 121,14 mek/10ogram untuk zeolit dari ampas tebu sedangkan 90 mek/10og untuk zeolit dari abu sekam padi. Semakin besar konsentrasi $\mathrm{NaOH}$ nilai KTK dari zeolit hasil sintesis cenderung turun, hal ini menunjukkan semakin berkurang muatan negatif pada $\mathrm{Al}$ dan semakin berkurang juga kation $\mathrm{Na}^{+}$yang dapat dipertukarkan atau jumlah Si semakin meningkat dibandingkan Al di dalam zeolit sintesis. 
Tabel 1: Hasil Kapasitas Tukar Kation (KTK) Zeolit hasil sintesis.

\begin{tabular}{ccc}
\hline Zeolit & $\begin{array}{c}\text { KTK1 } \\
\text { mek/100 g }\end{array}$ & $\begin{array}{c}\text { KTK2 } \\
\text { mek/100g }\end{array}$ \\
\hline ZA1 & 121,14 & 90,00 \\
ZA2 & 90,91 & 55,56 \\
ZA3 & 118,92 & 66,67 \\
ZA4 & 100,00 & 78,72 \\
ZA5 & 96,86 & 65,71 \\
\hline
\end{tabular}

\section{Kemampuan Detergensi}

Tabel 2 detergensi surfaktan sodium lauryl sulphat (SLS) dengan Builder zeolit sintesis

\begin{tabular}{ccc}
\hline Sampel* & $\begin{array}{c}\text { Rata-rata \% } \\
\text { Deterjensi Abu } \\
\text { ampas tebu }\end{array}$ & $\begin{array}{c}\text { Rata-rata \% } \\
\text { Deterjensi Abu } \\
\text { sekam padi }\end{array}$ \\
\hline S1 & 93,57 & 85.60 \\
S2 & 89,42 & 87.14 \\
S3 & 92,34 & 92.33 \\
S4 & 89,88 & 93.39 \\
S5 & 85,97 & 94.31 \\
STPP & 73,61 & 70.47 \\
Tanpa builder & 48,70 & 85.60 \\
\hline
\end{tabular}

*S1 - S5 yaitu surfaktan dengan penambahan zeolit sintesis dengan variasi konsentrasi $\mathrm{NaOH} 1,67 ; 3,33 ; 5$; 6,67 dan $8,3 \mathrm{M}$

Tabel 2 menunjukkan bahwa zeolit hasil sintesis dari abu ampas tebu memiliki kemampuan sebagai builder surfaktan lebih baik dibandingkan dengan STPP (Sodium Tripoli phosphat). Hasil detergensi optimal diperoleh pada sampel S1 dengan konsentrasi $\mathrm{NaOH}$ sebesar 1,67 M dan detergensi $93,57 \%$. Sedangkan untuk zelit sintasis dari abu sekam padi, detergensi optimum pada sampel S5 yaitu konsentrasi $\mathrm{NaOH} \mathrm{8,3} \mathrm{M}$ dengan detergensi sebesar $94,31 \%$. Fungsi builder pada detergensi antara lain adalah mengikat kation $\mathrm{Ca}$ dan $\mathrm{Mg}$ pada airsadah dan mempertahan $\mathrm{pH}$. Mengikat kation $\mathrm{Ca}$ dan $\mathrm{Mg}$ pada airsadah berkaitan dengan KTK zeolit, semakin tinggi KTK makin banyak kation Ca dan Mg yang dapat diikat oleh builder sehingga kation-kation tersebut tidak mengganggu proses dertegensi dan detergensi dapat meningkat. Hal ini sesuai untuk zeolit sintesis dari abu ampas tebu, tetapi pada zeolit sintesis dari abu sekam padi tidak demikian. Abu sekam padi mengandung silika yang sangat tinggi sehingga untuk mengambil silika dibutuhkan konsentrasi $\mathrm{NaOH}$ yang lebih tinggi. Detergensi juga dipengaruhi $\mathrm{pH}, \mathrm{pH}$ optimum berkisar 10-11, 5 atau $\mathrm{pH}$ basa karena ada pengaruh muatan negatif $\left(\mathrm{OH}^{-}\right)$yang terdistribusi pada kain dan kotoran sehingga kotoran mudah terlepas. Larutan surfaktan dengan penambahan zeolit sintesis dari abu sekam padi mencapai pH optimum pada konsentrasi $\mathrm{NaOH}$ 8,3 $\mathrm{M}$.

\section{Kesimpulan}

Jenis mineral zeolit yang terbentuk dari bahan dasar abu ampas tebu dan abu sekam padi antara lain zeolit A, Na-A, Na-Y dan sodalit. Morfologi zeolit hasil sintesis dengan konsentrasi $\mathrm{NaOH}$ 1,67 M cukup homogen dengan ukuran grain kristal rata-rata kecil, sedangkan konsentrasi $\mathrm{NaOH}$ 8,33 $\mathrm{M}$ kurang homogen dengan grain kristal rata-rata besar. Nilai KTK dan Uji deterjensi menunjukkan hasil optimal pada konsentrasi $\mathrm{NaOH} 1,67$ M masing-masing yaitu 121,14 mek/100 gram dan 92,09 $\%$ untuk zeolit sintesis dari abu ampas tebu dan pada konsentrasi $\mathrm{NaOH} \mathrm{8,3} \mathrm{M} \mathrm{yaitu} \mathrm{65,71} \mathrm{mek/100} \mathrm{gram} \mathrm{dan}$ $94.31 \%$ untuk zeolit sintesis dari abu sekam padi.

\section{Daftar Pustaka}

[1] Chandra Wahyu Purnomo, Chris Salim, Hirofumi Hinode, Synthesis of pure $\mathrm{Na}-\mathrm{X}$ and $\mathrm{Na}-\mathrm{A}$ zeolite from bagasse fly ash, Microporous and Mesoporous Materials, $\quad 162, \quad$ (2012) 6-13 http://dx.doi.org/10.1016/j.micromeso.2012.06.007

[2] Chun-Feng Wang, Jian-Sheng Li, Lian-Jun Wang, Xiu-Yun Sun, Influence of $\mathrm{NaOH}$ concentrations on synthesis of pure-form zeolite A from fly ash using two-stage method, Journal of Hazardous Materials, 155, $\quad 1, \quad$ (2008) 58-64 https://doi.org/10.1016/j.jhazmat.2007.11.028

[3] Pungki Hanipa, Pardoyo Pardoyo, Taslimah Taslimah, Arnelli Arnelli, Yayuk Astuti, Pengaruh Variasi Waktu Hidrotermal terhadap Sintesis dan Karakterisasi Nanokristal Zeolit A dari Abu Sekam Padi, Jurnal Kimia Sains dan Aplikasi, 20, 2, (2017) 7983 https://doi.org/10.14710/jksa.20.2.79-83

[4] K. S. Hui, C. Y. H. Chao, Pure, single phase, high crystalline, chamfered-edge zeolite $4 \mathrm{~A}$ synthesized from coal fly ash for use as a builder in detergents, Journal of Hazardous Materials, 137, 1, (2006) 401-409 https://doi.org/10.1016/j.jhazmat.2006.02.014

[5] J. S. Udhoji, Amit Kumar Bansiwal, S. U. Meshram, S. S. Rayalu, Improvement in optical brightness of fly ash based zeolite-A for use as detergent builder, Journal of Scientific and Industrial Research, 64, (2005) 367-371

[6] Milton J Rosen, Joy T Kunjappu, Surfactants and interfacial phenomena, John Wiley \& Sons, 2012.

[7] Arnelli Arnelli, Noor Afifah, Narita Rizki, Tri Windarti, Yayuk Astuti, Synthesis of Zeolite from Sugar Cane as Detergent Builder: Variation of Si/Al Ratio and Hydrothermal TimeSynthesis of Zeolite from Sugar Cane as Detergent Builder: Variation of $\mathrm{Si} / \mathrm{Al}$ Ratio and Hydrothermal Time, Jurnal Kimia Sains dan Aplikasi, 21, 1, (2018) 24-28 https://doi.org/10.14710/jksa.21.1.24-28

[8] Arnelli Arnelli, Fitriani Solichah, Alfiansyah Alfiansyah, Ahmad Suseno, Yayuk Astuti, Sintesis Zeolit dari Abu Sekam Padi menggunakan Metode Hidrotemal: Variasi Waktu dan Temperatur, Jurnal Kimia Sains dan Aplikasi, 20, 2, (2017) 58-61 https://doi.org/10.14710/jksa.20.2.58-61

[9] Jean-Francois Le Page, Applied heterogeneous catalysis: design, manufacture, use of solid catalysts, Technip, 1987. 